\title{
Exergy cost of mineral resources
}

Rui N. Rosa*

Physics Department and Geophysics Center, University of Évora, 7000-671 Évora, Portugal

Fax: +351266745394_E-mail: rrosa@uevora.pt

${ }^{*}$ Corresponding author

\section{Diogo R.N. Rosa}

INETI-Geociências, Estrada da Portela, Alfragide, 2720-866 Amadora, Portugal

Geology Department and CREMINER, University of Lisbon, 1749-016 Lisboa, Portugal E-mail: diogo.rosa@ineti.pt

\begin{abstract}
Mineral deposits are considered as natural capital whose value can be assessed in exergy terms. Historical industry experience provides evidence that exploitation of mineral deposits and the beneficiation of ores are essentially energy intensive. The persisting decline of the grade of the developed deposits demands increasing exergy replacement and processing costs. The results demonstrate how far processed ores and concentrates are from ideal behaviour, and technologies from reversibility conditions. The exploitation of mineral resources of declining quality for mineral commodities imply a long time trend of increasing mass and exergy inputs spent per unit product output, in line with a law of 'diminishing returns' on invested exergy.
\end{abstract}

Keywords: exergy; entropy; mineral resources; ore grade; recovery ratio; concentration.

Reference to this paper should be made as follows: Rosa, R.N. and Rosa, D.R.N. (2008) 'Exergy cost of mineral resources', Int. J. Exergy, Vol. 5, Nos. 5/6, pp.532-555.

Biographical notes: Rui N. Rosa graduated in Physics and Chemistry, and also holds a PhD in Physics. He currently conducts research in energy related topics, namely resources depletion, and atmospheric physics at the Évora Geophysics Center, and is a full Professor at the Department of Physics of the University of Évora.

Diogo R.N. Rosa graduated in Geology and holds a PhD in Economic Geology. $\mathrm{He}$ has worked in several mineral exploration projects. He currently conducts research on the metallogenesis and igneous geochemistry of the Iberian Pyrite Belt, with the INETI-Geological Survey of Portugal. Additionally, he teaches at the Geology Department of the University of Lisbon. 


\section{Introduction}

Ore deposits and hydrocarbon reservoirs are natural bodies which hold exceptionally highly concentrated exergy. However, further exergy has to be spent in extracting and processing the raw materials from Earth, in order to produce commodities, final goods and services to the economic sphere. For mineral commodities in general, the increasing exergy cost of extraction and production is an indicator of depletion. In extracting or capturing energy resources, increasing exergy cost per unit product indicates depletion, the exergy expenditure per exergy delivered becoming then a limiting factor of energy availability.

Exergy content accounts for the thermodynamic distance from a state of reference representing the environment. It comprises physical and chemical exergy. The latter accounts for the energy stored in the atomic bonds of molecules in relation to the binding energy of every constitutive element in the reference state. When different species are mixed, besides the chemical exergy of each one, a mixing exergy has to be considered too. This is the case of minerals in a rock.

When extracting a chemical or mineral species from the crust or the sea-water, one cannot ignore that the whole process is a chain of technical procedures, in which molecular or atomic bonds are broken at progressively smaller scales, and different species are separated, until the desired product is attained. Exergy has to be spent at every step in the process.

In the mining of ore deposits, rock blasting, crushing, grinding and milling are mechanical steps in a size reducing process, required to liberate and un-mix mineral species. Separation is a very exergy intensive process. Physical or chemical methods - such as inertial, magnetic, aerodynamic, hydrodynamic, flotation, ion-exchange or other - are used to separate the mineral species of interest. When the final product is a chemical element, pyrometallurgical (smelting or roasting) or hydrometallurgical (leaching, precipitation, ion-exchange, electrolysis and so on) processing assisted by chemical reagents break the final bonds and liberate the desired element.

Separation or un-mixing exergy is often referred to either as a serious limitation or rather an irrelevant contribution to the extraction of particular mineral commodities. This point ought to be clarified. First, mixing entropy and the correspondent separation exergy reflect the proportion of the constitutive substances in the mixture; they both exhibit a logarithmic dependence on the relative molecular contents, but this applies strictly to ideal gases or ideal solutions, in the absence of molecular interactions. When the constituents are interacting like solutes in a strong solution or minerals in a rock, the binding energy is also reflected in the entropy of the mixture, through the ionic activity or the interfacial energy, and separation exergy becomes larger. Secondly, actual separation processes are not perfect at all, and the exergy actually required can be quite larger than the theoretical limit. The reason is that in the technical separation one has to work far away from ideal state and equilibrium conditions, in order to maintain economic throughputs, so that molecular interactions cannot be avoided and dissipative losses are always present. Thirdly, the species to be separated can have rather similar properties, such that the separation factor of an individual step might be very low and accordingly the un-mixing process might require a long multistage procedure, thereby adding to exergy wastes and losses. For instance, separating water in desalination is far less exergy demanding than enriching uranium (for equivalent molar amounts); and in both cases the 
exergy expenditure per unit product increases sharply with increasing degree of attained separation.

Breaking bonds down to crystal grain or to atomic levels requires the expenditure of exergy; some of this spent exergy might be recovered (by means of heat regeneration or reagent recycling and so on) but all stages generate wastes and are irreversible to some extent; some of them are entirely irreversible (such as crushing rock).

This paper emphasises how far ores and concentrates are from ideal behaviour and technologies from reversibility conditions. One should realise the limits to the growth of production of certain mineral products.

\section{The exergy measure of natural capital}

The intensive use of natural resources is progressively depleting reservoirs formed over geological times. At the same time large quantities of wastes and effluents are impacting upon the natural cycles of our planet. Controlling resource use and anthropogenic emissions constitute a concern to be pursued for a sustainable relation of Man with Nature. In this context it is of great importance to adopt a general and physically sound measure for accounting for both resources exploitation and wastes emission.

Exergy has been suggested as the most suitable indicator for both resource and waste accounting (Szargut, 2005). Nonetheless, for historical reasons resources have been always divided in two categories, namely fuels measured in energy units and mineral, agricultural or forest raw materials or derived commodities measured in a variety of mass units. This distinction leads to incongruities, as the choice of a different unit for each flux is a barrier for evaluating all inputs and outputs on a comparable basis.

The adoption of exergy as a general indicator for resource accounting would improve the situation in four significant ways. First, the exergy measure automatically combines both mass and energy flows in a concise representation. Second, the exergy measure takes automatically into account both the first law (energy conservation) and the second law (entropy generation) of Thermodynamics. Third, exergy efficiency is a suitable tool to assess technological development and to identify technical steps or paths of improvement. Fourth, it enables the evaluation of all materials, in terms of the minimum energy requirement for extraction, separation and refining. Scarcity can thus be measured. Finally, the chemical exergy measures the thermodynamic distance from the equilibrium with a reference environment. As such, it offers first-order information on the environmental impact associated with the release of wastes (Ayres et al., 2006).

\subsection{Exergy of mineral resources}

A mineral deposit is an exceptional circumstance in nature.

From the point of view of its genesis, geological agents realised useful work in transporting and concentrating certain mineral species from a reference undifferentiated environment up to the actual deposit. From the economic point of view, one still has to spend some amount of useful work in extracting and processing those minerals, transforming them by technical means, to realise its utility as a commodity. However, less effort is needed to extract such minerals as compared to other parts of the Earth's crust, due to its exceptional chemical composition and grade. 
The standard chemical exergy of a particular element in a mineral deposit comprises two components: the reaction and the concentration contributions. The first one is the minimum amount of energy required to break and rearrange the bonds that unite the reference substance in order to isolate the particular element. This reaction component can be positive or negative, depending on the stability of the reference substance compared to the native element. The second component provides information about the minimum amount of work needed to concentrate the reference substance of the given element from a 'reference environment' that is similar to the real environment, but completely dispersed. The concentration contribution is always positive.

Following this approach, a mineral deposit is an infrequent aggregate of rocks, which are aggregates of mineral grains, these being aggregates of molecular species, which in turn are organised aggregates of atoms. So, the genesis of a mineral deposit can be represented by the following expression (Valero et al., 2002):

$$
\text { Mine }=\sum \text { rocks }=\sum \sum \text { minerals }=\sum \sum \sum \text { molecules }=\sum \sum \sum \sum \text { atoms. }
$$

At each level, the aggregate is characterised by a cohesion or bond energy that coincides with its formation enthalpy, and its mixing entropy that is related to the improbability of occurrence of the corresponding aggregate.

Thermal interchanges are nil during a process of ideal mixing; however solid solutions in a mineral and mixes of minerals in a rock matrix are not ideal mixtures. In the limit of an ideal mixture of various components having molar fractions $x_{i}$, the entropy of the mix is given by the classic expression (Callen, 1985), $R$ being the universal gas constant:

$$
\Delta S=-R \sum x_{i} \log x_{i}
$$

The standard chemical exergy of a compound is the minimal energy required to form a compound starting from the elemental species in the standard state. It is obtained from the standard Gibbs' free energy of formation $\Delta G_{\text {form }}$, and the standard exergy $b_{k}^{o}$ of each element $k$ that contributes with $v_{k}$ molecules to the formation reaction, by means of the expression (Szargut, 2005):

$$
b_{\text {chem }}=\Delta G_{\text {form }}+\sum v_{k} b_{k}^{o} \text {. }
$$

Analysing the tables of chemical exergy computed from alternative reference species (per chemical element) or reference environments (crust, seawater or atmosphere) one realises that stability does not coincide with abundance in a number of cases; for instance, some minerals quite abundant in Nature, such as massive sulphides, have a fairly high chemical exergy (Valero et al., 2002). This finding reflects the reality that the Earth is not in a 'dead state', its metabolic activity being driven by the solar radiation flux and the geothermal heat reservoir (Szargut, 2005).

The combination and concentration of chemical elements and minerals in a mineral deposit can be viewed as a 'natural capital' endowment. The minimum theoretical work spent by Nature to realise such outcome, starting from a hypothetically degraded Earth as the reference environment, although not replicating the geological processes at work, has been proposed as the appropriate measure of that natural capital. The amount of the resource and its replacement cost, once explored, can accordingly be both assessed in exergy terms. 
In order to realise the economic utility of the natural capital as a mineral commodity, a chain of technical steps, namely (in short) mining, hauling, milling, concentrating and refining, have to be taken. Given a mineral deposit, the minimum theoretical energy that must be invested to proceed towards obtaining one kmol of product is given by:

$$
b_{\text {mix }}=-R T_{\mathrm{o}}\left[\log x+\frac{(1-x)}{x} \log (1-x)\right]
$$

at the concentrating stages, for a particular element occurring at molar fractions $x$, plus a given theoretical amount of energy at the extractive or refining stage, given by:

$$
b_{\text {chem }}=\Delta G_{\text {react }}+\sum v_{k} b_{k}^{o}
$$

$\Delta G_{\text {react }}$ being the standard Gibbs' free energy of reaction and $b_{k}^{o}$ the standard exergy of each reagent $k$ that contributes with $v_{k}$ molecules to the extractive reaction.

The exergy required to mine-concentrate the ore of a certain mineral product is, as a rule, larger than exergy required to extract-refine the final product from its concentrate. And actual technical energy expenditures are usually much larger than the minimum theoretical estimates, mostly so in what concerns the concentration stages. Figure 1 illustrates the minimum energy requirements for concentrating $E_{\text {conc }}$ and refining $E_{\text {refine }}$ from mine to final product. In any case, it is a fundamental issue that, the lower the concentration of the product in the ore, the greater the energy needed to extract the resource; that is why mineral deposits are valuable for their grade and higher grade deposits are exploited first.

Figure 1 Minimum energy requirements for concentrating $E_{\text {conc }}$ and refining $E_{\text {refine }}$ from mine to product

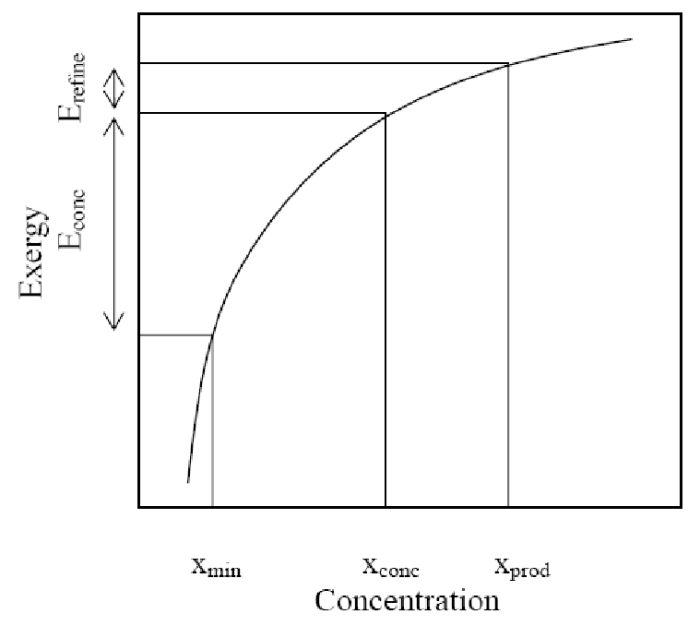

\section{Depletion of mineral resources}

The physical limitations to mineral exploitation in deposits with small tonnages or low concentrations have been brought up by several authors - see Kellogg (1977) and Chapman and Roberts (1983). 
Mineral resources are developed first where large, high grade and accessible deposits are found. As higher grade reserves are progressively depleted, the ore grades that are mined gradually move down. More resources are available at lower grades and at less accessible deposits, but then mining and processing energy needs become higher and larger amounts of overburden and wastes impact more heavily on the environment. This course of events is already undeniable in a number of major mining provinces in the World.

For example, the average grade of copper ore mined in the USA over the last century has declined drastically as the production accumulated. This reduction in grade has a dramatic effect on the energy consumption in further production of refined copper, accompanied by greenhouse and acid rain gas emissions from the metal production processes. Similar trend and impacts have been reported for refined nickel production (Norgate and Rankin, 2000), but nickel metal production was several-fold more energy intensive than copper metal production. For both commodities, life cycle assessments reveal that more modern hydrometallurgical processes involving solvent extraction and electro-winning had higher energy consumptions than the more conventional pyro-metallurgical processes, and limited success in reducing emissions.

Further examples are reported for Canada, a country that has shared with Australia the condition of World's largest mineral commodities producer and exporter. A comprehensive study was released recently on the historical record of reserves and production since the late 19th century (Cranstone, 2003). It is realised, as a particularly stark example, that the life cycle of lead production in Canada reveals that the tonnage of lead contained in mineable ore is in steep decline (ten fold) since the early 1980s.

Other examples are reported about the mining industry in Australia. The general historical trend observed in Australia is that reserves have increased with time, but one realises that it has been mostly by adding resources to reserves. The most depleted mineral commodities in Australia are $\mathrm{Au}, \mathrm{Ag}, \mathrm{Pb}$ and $\mathrm{Zn}$, having so far experienced decreases of $68,64,60$ and $53 \%$ of their 2004 (mined and remaining) ultimate reserves, respectively. If the rates of exploitation remain at the 2004 level, the reserves will last about 22, 19, 34 and 28 years, respectively (Valero et al., 2006).

Considering a particular commodity of great industrial importance, the compilation of statistical data on world production of copper shows a steady increase with no indication of a significant slow down. However, the data pertaining to the USA (US Geological Survey, 2006) indicates that production in this important producer may have already peaked in 1997 and has since fallen by almost half, despite the recent increase in prices. Another significant producer, Canada, has also passed its copper production peak (Cranstone, 2002). This suggests that large areas, encompassing diverse geological settings, can peak, despite their developed infrastructure and favourable economic conditions. As this happened, the copper grade of the ores mined has declined steadily over the past century (Ruth, 1995), reflecting the decreasing resource availability. Undoubtedly, world production is increasing because it has been expanding into new regions, namely South America with its low grade copper porphyries, as mature regions achieve their peak. Ultimately, as the new regions will also peak, it seems likely that the World as a whole will reach its copper peak (Rosa and Rosa, 2006a).

As Chapman and Roberts (1983) argue, the world is now more developed and better explored, so that it became increasingly difficult to find regions worthy of further exploration efforts. As a rule, discovery is slowing down, and primary production is already declining for certain minerals and commodities. 
It is in such contexts that recycling (secondary production) becomes an important alternative to primary production (Norgate and Rankin, 2002). Recycling rate targets must take into account market growth, metal product lifetime and the nature of the product itself (say electrical cables vs. electronic scrap). The maximum amount of a material that can be recovered at any time is a function of the quantity put into service one average product lifetime before; the lifetime of copper was estimated a weighted average of 17 years. It is likely that advances in technology will help improve recycling efficiency and economics but recycling does not avoid energy costs (that can be high for certain scrap products) and cannot resolve the desire for increasing the economic inventory of the commodity.

\section{Regularity laws in mineral exploration and extraction}

\subsection{Tonnage and grade}

Quantifying mineral resources requires the compilation of grade and tonnage data of prospected mineral deposits. Cox and Singer (1986) found that, in well explored provinces, frequency distributions of ore deposits relative to both size and to average grades, display a recurrent pattern. According to Singer (1993), the model is close to a lognormal distribution for both tonnage and grade, without any significant correlation between these two variables.

Reserves are dominated by the very few largest ore deposits. Low-grade and particularly low-tonnage deposits are likely underrepresented in the data sets, because they are less likely of being detected for a given prospect effort, so that the lognormal model may represent a biased sample with regard to an actual larger number of low-grade or small-tonnage deposits.

Historical data on mineral production also confirms a similar relationship between cut-off ore grade and cumulative production. Such data was first studied by Lasky (1950), who proposed a negative linear correlation between log cumulative tonnage and average grade, for many elements. On the basis of geo-statistical research published between 1960 and 1980 by Skinner (1979) and Harris (1984), Chapman and Roberts (1983) and de Vries (1988) worked out the basic concepts for describing past and anticipating future trends of average ore grades for important metals. An operational relationship was established between the cumulative quantity mined since the beginning of modern age $Q$ and the corresponding evolution of the average ore grade $g$, which reads as:

$$
\log Q=c-m \log g .
$$

This equation does not express a strict relationship but rather an observed and expected trend. Underlying this equation is the assumption that the cumulative quantity, from the highest ore grade down to a certain grade class of a particular metal, in the accessible Earth crust, is normally distributed with respect to the logarithm of the ore grade. The lognormal distribution exhibits linear fractal behaviour at the lower side range of $Q$ and higher range of $g$; it is this self-similarity that is translated by equation (5). Notice that the linear fractal overestimates the reserves if these are correctly represented by a lognormal distribution but, on the other hand, as stated above, the later is likely underestimating the lower quality (vis a vis tonnage and grade) resources. 
The values of parameter $m$ originally offered by Chapman and Roberts (1983) ranged from the bracket $(1 ; 3)$ for $\mathrm{Cu}, \mathrm{Hg}$ and $\mathrm{Ni}$, up to the bracket $(17 ; 25)$ for $\mathrm{Cr}, \mathrm{Mn}$ and $\mathrm{Al}$. For instance, looking at records from 1940 to 1977 in the USA (Cargill et al., 1981), one finds that increasing by a factor of 10 the cumulative quantity of ore extracted resulted in a grade decrease of $50-60 \%$ for copper and of $80-85 \%$ for mercury.

de Vries (1988) proposed later an interpretative model that starts with a hypothetical crust where elements are initially uniformly dispersed and then one is transferred from depleted sub-volumes into enriched sub-volumes, at ever smaller scales and higher and lower grade levels, by a series of virtual geological processes. As the final result of these geological operations, the particular metal content of the crust is log normally distributed with respect to ore grade. This distribution was determined for a certain number of metals; modelled data shows that metals may exhibit strong, medium or small decrease of expected average ore grade, when the cumulative extracted quantity grows; according to this classification, de Vries (1988) named the first group (such as Fe, Al, Mg, Ti) abundant elements, the second group (where he included $\mathrm{Ni}, \mathrm{Zn}, \mathrm{Cu}, \mathrm{Pb}$ ) medium abundant elements, and the third group (where he included U, As, Sb, Ag, Hg) scarce elements.

\subsection{Learning curves and recovery rates}

Technological advances have enabled the enlargement of mineral reserves, by means of improvements in the exploration, extraction and recovery methods. But all these lines of progress face intrinsic physical constraints.

The availability and eventual depletion of certain metals was addressed by Ruth (1995), who considered not only the decline of average ore grades, but also the technical improvements in energy use in mining and in refining the same metals - commonly expressed as 'learning curves', that tell the rate at which the theoretical limit of energy expenditure has been approached, given the past industry experience.

For the case of copper in the USA, this author found, for the change in ore grade in copper mining:

$$
\log g(t)=0.335-0.3141 \log Q(t)
$$

that is of the form of equation (5) proposed by Chapman and Roberts (1983). On the other hand, he found:

$$
\begin{aligned}
& \log \left[e(t)-e^{\prime \prime}(t)\right]=10.292-0.953 \log Q(t) \\
& \log \left[e(t)-e^{\prime}(t)\right]=12.591-0.208 \log Q(t)
\end{aligned}
$$

as the learning curves of energy use in copper mining and in copper smelting and refining, respectively. Whereas the material waste generation per ton of ore produced in copper mining was nearly constant.

The minimal energy expenditures $-e^{\prime}$ and $e^{\prime \prime}-$ and the limitations in attaining them will be addressed more closely further on. However, a generally decreasing ore grade brings into play two important consequences: the growth of the dilution factor and the decline of the recovery rate, which translate into fast growing extracted and processed masses and energy demand, as well as waste, per unit mass of final product. The dilution 
factor, that is the mass of rock to be processed per unit product mass, grows in the inverse proportion of the ore grade; this is a mathematical relationship and does not depend on technology or ore type. Data on the recovery rate or yield $Y$ of the targeted substance in mining, milling and concentrating ores show that it decreases with the declining ore grade, as the masses of extracted, processed and discarded materials jointly grow; this is a thermodynamic consequence.

The energy cost of extracting a unit mass of substance $J$ is finally given by the energy expenditure in mining, milling, and concentrating per unit mass of ore $C$, divided by the joint recovery rate or yield $Y$ and by the mass fraction or grade $g$ of the substance in the ore:

$$
J=C / g Y .
$$

The evaluation of this equation reveals the reach and the limit of the extraction of mineral substances.

\subsection{A relevant case study}

Uranium is a particular commodity given the fact that it is exploited mostly as a nuclear fuel for the 'production' of electrical energy; the energy costs of extraction and refining become therefore decisive factors in justifying its exploitation.

In the case of uranium, the distribution of ore tonnage with grade is shown in Figure 2, after Chapman and Roberts (1983); according to this distribution, almost $100 \%$ of the crustal quantity of the metal is contained in rocks of grade $3 \mathrm{ppm}$ or better, while ore grades $1 \%$ or better contain no more than $1 / 10000$ of the total crustal quantity. This cumulative curve can be approximated by a straight line in the upper range of ore grade classes.

Figure 2 The cumulative probability for a log-normal distribution

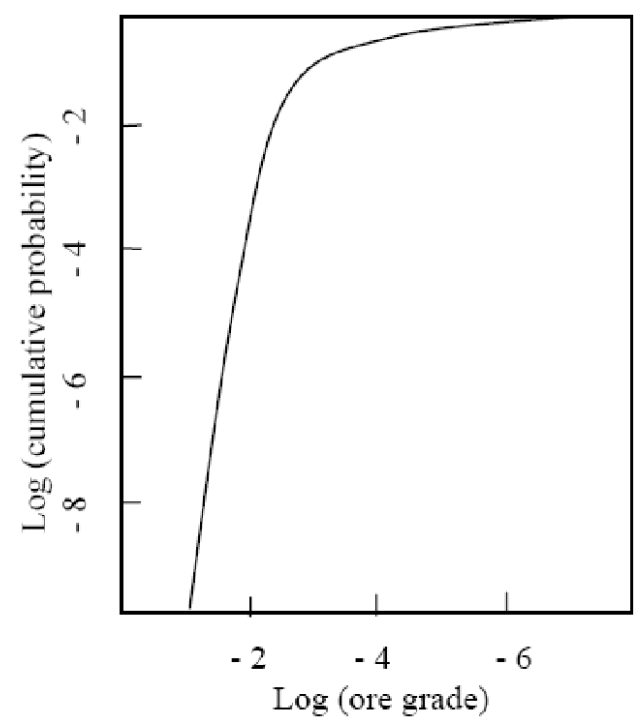

Source: Adapted from van Chapman and Roberts (1983) 
It is an element which is currently extracted from a variety of mines - from ores with grades down to about $0.01 \% \mathrm{U}_{3} \mathrm{O}_{8}$. The cut-off grade is an economically critical parameter. The effect of changing the cut-off grade in a number of uranium deposits has been examined by the IAEA; the fraction of the total metal content that is recovered from the mine correlates negatively with cut-off grade - very rapidly when the average grade is low; and the average grade of extracted ore increases almost linearly with the cut-off grade in every case. So that lowering the cut-off grade increases the fraction of metal in situ that is recovered but, as it will be seen soon, at growing energy unit cost and decreasing recovery rate at the beneficiation stages (International Atomic Energy Agency, 1996).

Data on the yields of uranium mines show that the recovery rate of the metal in situ decreases fast at the lower ore grades; the yield drops to below $70 \%$ for grades smaller than $0.01 \%$; from there on the yield declines precipitously, although a small number of laboratory studies on mining and milling of unconventional ores provide results that suggest that a $30 \%$ yield might still be attained at $0.001 \%$. Figure 3 displays the trend of the overall recovery rate of uranium as a function of ore grade. The following interpolation has been proposed by van Leeuwen (2006):

$$
Y=a-b \log ^{2}(g)
$$

The size of uranium resources grows fast with decreasing ore grade (for grades well above the crustal average). But due to the dilution factor and the extraction yield, the energy cost of unit product increases fast with decreasing ore grade; consequently the net available energy in uranium resources, as function of the ore grade, will reach a peak at some grade, which has been set at about $0.05 \%$ by van Leeuwen (2006).

Figure 3 Overall recovery rate of uranium as a function of ore grade

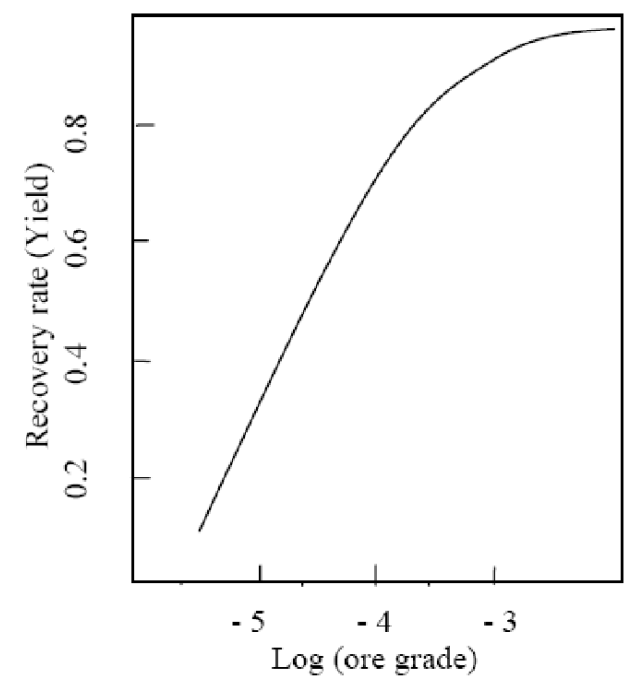

Source: Adapted from van Leeuwen and Smith (2005)

The bulk of Australian uranium is contained in the huge Olympic Dam mine, the third in the World regarding reserves and production rate. The uranium grade at Olympic Dam is very low, averaging about $0.04 \% \mathrm{U}_{3} \mathrm{O}_{8}$ for the full resource as of March 2005 
(University of Sydney, 2006). Assuming a minimum grade of about $0.01 \% \mathrm{U}_{3} \mathrm{O}_{8}$ to ensure an overall positive energy return, Olympic Dam uranium is only returning a marginal energy payback, that is, a small net energy life-cycle output (apart the benefit from copper, gold and silver concurrent production). A particular issue with Olympic Dam is the occurrence of brannerite, a uranium mineral that is highly refractory and has been effectively dumped in tailings, thereby implying the low recovery rate at the site to date (Mudd, 2005).

\section{$5 \quad$ Mining and ore processing}

From the rock matrix till the pure state, obtaining a particular substance requires a more or less lengthy chain of technical steps. The first ones are mechanical, namely crushing, breaking and milling, aiming at extracting and size reducing the raw-material of interest. Concentration of a particular mineral species can be carried out by means of a variety of physical or chemical procedures, taking advantage of the differences of properties of the minerals in presence. To the stream of processed material, at each stage of ore beneficiation there are added inputs of mass and useful energy and subtracted outputs of waste mass and degraded energy, as shown in the Figure 4. At every stage the added exergy is divided among embodied, wasted and lost (dissipation) fractions, and the substance being extracted is divided between recovered and wasted fractions; losses are unavoidable at each and every step.

Figure 4 Chain of processing and concentration stages of a raw-mineral

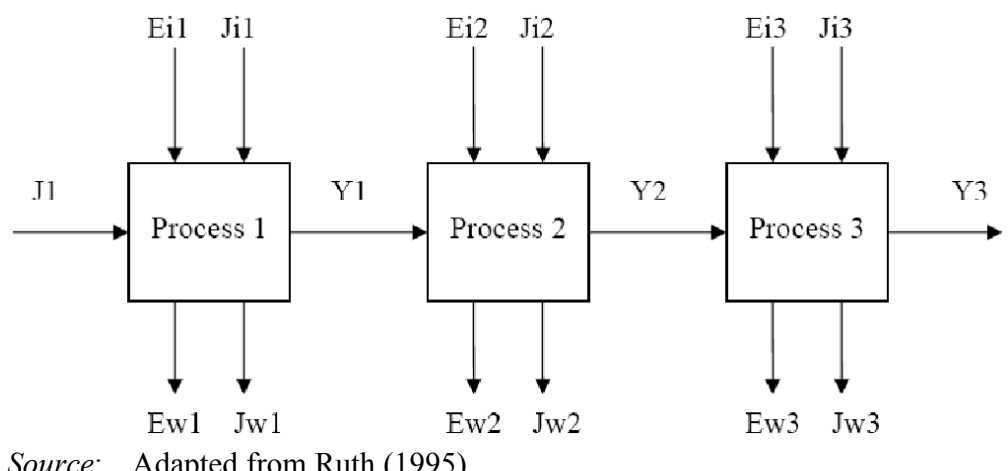

Source: Adapted from Ruth (1995)

Later on, at the refining stage, the elements of interest can be isolated in pyro-, hydro-, electro- or bio- metallurgical processes, with the assistance of exergy inputs in the form of heat, chemicals, electricity or enzymes.

Blasting and breaking rock, extracting and hauling the useful ore fraction, and crushing, grinding and milling this into a fine product, prone to subsequent mineral separation, are the mechanical procedures of the mining and beneficiation phase. These mechanical processes are highly energy intensive, mostly so when the grade is low, which implies that the proportion of moved rock mass is large and/or the size reduction of the ore has to be carried on till a very fine product.

Besides ore type and grade, the specific energy requirements for mining also depends on the amount of overburden in the case of open pit mining and on the depth of the ore 
body in the case of underground mining. Taking uranium as a study case, it is mined in open pit mines when the ore bodies are not deeper than about $200 \mathrm{~m}$ and the stripping ratio is not larger than about 30 (that means that to recover a unit mass of ore 30 unit masses of overburden has to be removed); the stripping ratio can affect the specific energy requirements by a factor of five, for a given ore type.

Kellogg (1977) proposed a model for the amount of energy spent in mining and concentrating a mineral product, given the ore grade $g$, the yield or recovery efficiency $Y$ in the extraction and concentration processes, and the specific energy expenditures in mining and concentrating - Um, Up. According to Kellogg (1977) Um depends essentially on the type of mining (underground or surface) and $U p$ on the physical-chemical characteristics of the ore. Kellogg suggests that both mining and the subsequent exploitation process are affected by the decrease in ore grade according to:

$$
U=\frac{(U m+U p)}{Y g} .
$$

Chapman and Roberts (1983) took into explicit account the efficiency of energy use in the mining, beneficiation and extractive metallurgic processes, offered the following to express the overall energy expenditure:

$$
U=\frac{E_{o}}{g \eta_{1}}+\frac{\Delta G}{\eta_{2}}
$$

where $E_{o}$ is the minimum energy required for mining, milling and concentrating, and $\Delta G$ the Gibbs free energy involved in converting the concentrate into pure metal; $\eta_{1}$ and $\eta_{2}$ are respectively the energy efficiencies of the extraction-concentration and the refining stages. This equation shows how the energy used in the metal production depends on the initial ore grade and the technology employed in obtaining the final product; but it overlooks the recovery factor (present in Kellogg's model) that is of great importance in poor ores.

More recently, Valero et al. (2002) assessed the whole mining, milling, concentrating and refining process chain, in the light of an exergetic analysis. The unit exergetic cost $k$ of a product has been defined as the ratio between the actual exergetic expenditure in obtaining that product and its theoretically computed exergetic content. This cost value is dimensionless and measures the number of units of exergy (useful, wasted and lost) actually spent in obtaining one exergy unit of a particular product. Empirical data shows that the exergetic cost $k$ can be one or several orders of magnitude; what is due to losses and irreversibilities in the actual technical processes employed by the mining and extractive metallurgy industries, as will be shown further on.

Fresh water plays also a paramount role as a processing mass flow input at most stages of the extraction of metals. Studies of industrial water consumption in extracting a number of metals (Norgate and Lovel, 2004) show it being strongly correlated to the grade of the ore, approximated by the formula:

$$
W=167 g^{-0.90}
$$

where $W$ stands for the 'cradle-to-gate' water consumption in $\mathrm{m}^{3} / \mathrm{t}$ refined metal, and $g$ the ore grade (in \%); one realises the huge water quantities used up by the mining industry, mainly so when low grade ores are exploited, as is also the case with the direct 
use of useful energy. Indirect water consumption in the metal production life cycle, in particular in the electricity generation, makes a significant contribution to the 'cradle-to-gate' water consumption for aluminium in particular. When expressing the 'cradle-to-gate' water consumptions as function of the mass of processed ore, the mean consumption is about $2.1 \mathrm{~m}^{3} / \mathrm{t}$ ore for a number of metals, while the mean value of water consumption at the mining and concentration stages is $0.7 \mathrm{~m}^{3} / \mathrm{t}$ ore, indicating that the 'cradle-to-gate' water consumptions is, on average, three times that of the mining and concentration stages, for the metals considered. Fresh water consumption also means an associated exergy input to the metal industry, that can be a rather high exergy cost.

\subsection{Size reducing: milling}

Milling means a physical transformation from a continuous to an increasingly discontinuous state of the fragmented material. The size reduction of a given mass of rock material implies the multiplication of particle numbers and therefore an increase of the entropy per unit mass in the order of $(k / \rho) / r^{3}, k$ standing for Boltzmann's constant and $\rho$ for the specific mass, irrespective of the free energy and entropy increments associated with the growth of the surface area. This means that mechanically processing ore rock consumes exergy that becomes partially embodied as physical exergy in the milled product.

Breaking and milling rock material, required before proceeding to the separation and concentration stage, yields granular or pulverised product whose size frequency distribution of particles has often been described as lognormal or alternatively as Weibull; both are self-similar on the side of smaller sizes. The cumulative frequency distributions $N, M$ of particle mass $m$ or of linear size $r$, have been of lately described as fractal, within a finite range:

$$
N(>r) \approx r^{-D s} \quad M(<r) \approx r^{h} \quad N(>m) \approx m^{-b}
$$

$D_{S}$ being the particle size fractal dimension and $\mathrm{D}_{\mathrm{R}}$, such that $2 D_{R}=D_{S}+3$, the particle roughness fractal dimension; as to the remaining exponents $h=\left(D_{R}-D_{\mathrm{S}}\right)$ and $b=D_{S} / 3$. As a matter of fact, the result of rock fragmentation by different means yields frequency distributions of particle properties that often exhibit fractal properties in size over two or three orders of magnitude having $2<D_{S}<3$, the larger particles contributing most to the product mass whereas the smaller ones to the surface area (Turcotte, 1992). This has been explained in terms of scaling laws of fragmentation. Sammis et al. (1986) in particular, proposed a comminution model to explain the autogenous fragmentation, which leads to a linear fractal having $D_{S}=2.60$, a value centred in the range exhibited by many distributions that have been observed in both geological and industrial environments.

Grinding and milling are needed for consequent beneficiation and in particular separation and concentration of the desired mineral fraction of the ore. In case of fine grain or of solid solution of a minor chemical species, the access and liberation of the desired species requires a very fine product to be attained, generating a high specific surface area, which implies a lengthy milling process at an high energy expenditure.

For a product described by a fractal frequency-size distribution of dimension $D_{S}$ in the range $r_{\max }<r<r_{\min }$ the specific surface area (area of surface $A$ per unit volume of product $V$ ) is given by: 


$$
A / V \approx\left(1 / r_{o}\right) \quad r_{o}=\left(r_{\max } / r_{\min }\right)^{3-D_{s}} r_{\min } .
$$

That is, the specific surface area varies as the reciprocal of $r_{o}$, which is a characteristic size of the particles in the distribution, given by the minimum particle size multiplied by a certain power of the geometrical amplitude of the size range; it becomes very high for very fine products.

Grinding and milling are often followed by classification of particle size, for recycling the larger particles, in a chain of stages, until a narrow size distribution of a small size class is reached, as depicted in Figure 5.

Figure 5 Chain of size reducing stages, with classification and recycling, till fine product

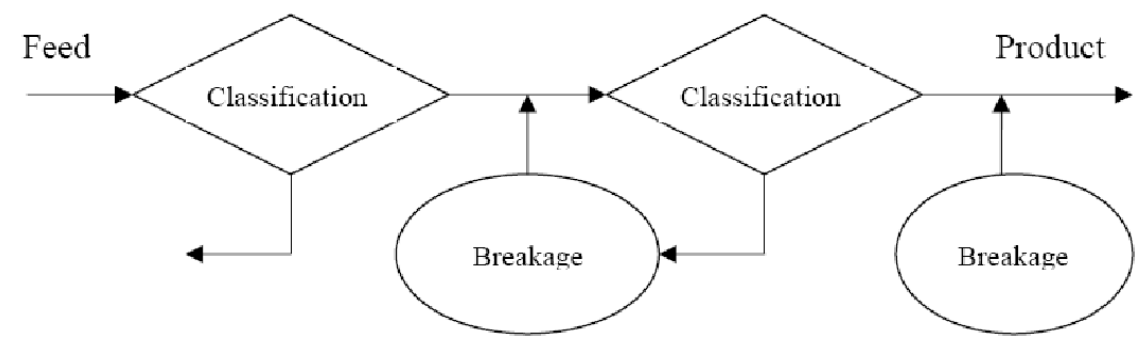

Mass balance equations written about each node of the grinding-classification chain describe the repetitive process of classification and breakage. Being $\mathbf{f}$ the feed size distribution vector, $\mathbf{p}$ the product size distribution vector, $\mathbf{B}$ the breakage distribution matrix (which gives the size distribution per size interval after a breakage event) and $\mathbf{C}$ the classification (diagonal) matrix (which describes the proportion of particles in each size interval entering the next fragmentation step). The Whiten model yields the formula (Donovan, 2003):

$$
\left.\mathbf{p}=(\mathbf{I}-\mathbf{C}) \bullet(\mathbf{I}-\mathbf{B C})^{-1} \bullet \mathbf{f}\right)
$$

I being the unit matrix. As stated above, exergy is spent in incrementing breakage and classification entropies of the material flow.

The generation of a high specific surface has important consequences upon the thermodynamic properties - in particular the chemical exergy of the processed ore. In a fragmented material, the thermodynamic properties comprise contributions of both the bulk (tri-dimensional) and the interface (bi-dimensional) phases - the later being no longer negligible in a finely divided product (Rosa and Rosa, 2006b). The Gibbs free energy $G^{*}$ and entropy $S^{*}$ per unit mass of product become, respectively (Sychev, 1981):

$$
G^{*} \approx G+\sigma v(A / V) \quad S^{*} \approx S-(\partial \sigma / \partial T) v(A / V)
$$

$v$ standing for the specific volume, $\sigma$ the surface tension; $G$ and $S$ are the contributions due to the bulk properties of the substance - as given in the thermodynamic tables - the added parcels being the contributions due the interface phase.

With respect to the bulk phase, fragmentation changes the magnitude of the properties according to:

$$
\Delta G \approx-S \Delta T+v \Delta P \quad \Delta S \approx c_{p}(\Delta T / T)-\beta v \Delta P
$$


$c_{p}$ standing for the specific heat and $\beta$ for the coefficient of thermal expansion of the substance. When comparing the properties of product at progressive stages of fragmentation, at standard reference conditions, temperature and surface tension (that is a sole function of temperature) do not change, while the pressure changes following Young-Laplace's law $\Delta P \approx\left(\sigma / r_{o}\right), r_{o}$ being the characteristic radius of the fragmented product. Therefore, changing the particle size along the milling process affects the bulk properties according to:

$$
\Delta G \approx v\left(\sigma / r_{o}\right) \quad \Delta S \approx-\beta v\left(\sigma / r_{o}\right) .
$$

As to the surface phase, the fragmentation increases the specific surface area according to $(A / V) \approx 1 / r_{o}$ (equation (13)). When comparing the properties of the product at progressive stages of fragmentation, there are increments in both the surface free energy and entropy, per unit mass of product, in the proportion of the growth of the specific surface, in the order of:

$$
\Delta\left[\sigma v(A / V] \approx(\sigma v) / r_{o} \quad \Delta\left[-(\partial \sigma / \partial T) v(A / V] \approx-(\partial \sigma / \partial T)\left(v / r_{o}\right) .\right.\right.
$$

The surface free energy change is comparable in magnitude and has the same sign as the simultaneous increment of the bulk free energy; whereas the entropy changes in the two phases have opposite senses (as $\partial \sigma / \partial T<0$ ). at proportional rates, but do not cancel out. At sub-micrometric sizes, the surface contributions to the thermodynamic properties exceed the values of the continuous state, and the magnitude of the properties of the pulverised product become far larger than their values at the standard state (Sychev, 1981). It should be recalled that the chemical exergy grows with the degree of fragmentation, in the inverse proportion of the linear particle size. It can be checked that the chemical exergy growth far exceeds the physical exergy growth associated with the increment of particle numbers. It is by now clear the thermodynamic foundations of the high energy expenditure in rock grinding and ore milling. A few empirically or theoretically based formulas have been put forward to quantify the amount of energy spent in size reducing between successive stages of separation, which can be unified in the formula (Charles, 1957):

$$
E \approx r^{-n+1} \quad \partial E / \partial d=-K / d^{n} .
$$

This energy-size relation (Walker-Lewis' relation) expresses the energy per unit mass spent in size reduction; the exponent is related to the fractal dimensions of the particles' roughness and size distribution, namely $n=1+D_{R}-D_{S}$ (Charles relation); according to different authors, who in fact dealt with different size ranges, $n=1$ (Kick), $3 / 2$ (Bond), 2 (von Rittinger) and 4, at progressively smaller sizes (Nagahama and Yoshii, 1994). The energy intensity of size reduction increases at an increasing rate as the size diminishes, as explained above. The foregoing thermodynamic approach anticipates exergy expenditures in agreement with von Rittinger's model $(n=2)$, what we interpret as meaning that both relate to the same high degree of fragmentation as attained in the mining industry, down to millimetric through micrometric size.

Mechanical processing of ore rocks consumes exergy that becomes partly embodied as chemical and to a lesser extent as physical exergy in the finely milled product and in the wastes. 


\section{Separation and concentration}

After fragmentation and milling, till a sufficiently fine product has been attained, the concentration of the chemical substance of interest requires, next, the separation of mineralogical species by physical or chemical methods. However, when the final product is an elemental species such as a metal, separation must be carried further by extractive metallurgy means.

Un-mixing exergy has been referred to as either a serious limitation or rather an irrelevant contribution to the extraction of particular mineral commodities. This point ought to be clarified. Mixing entropy, and the correspondent separation exergy, exhibits logarithm dependence on the relative molecular contents or grades, but this applies for an ideal gas and an ideal solution, in the absence of molecular interactions. It can strictly describe the extraction of gases from the atmosphere and to some approximation of ions from the sea water.

Given a mixture of non interacting particles, the separation of different classes of particles requires the expenditure of a minimum amount of work that is related to the mixing entropy; for one mole of particles, $x_{i}$ being the molar fractions of each class, the mixing entropy is given by:

$$
\Delta S=-R \sum x_{i} \log x_{i}
$$

This equation was originally established for ideal gases and applies strictly to mixtures of non interacting particles. The minimum energy required to un-mix the different classes of particles, the initial and final states being in equilibrium with the standard environment $\left(T_{o}, P_{o}\right)$, is Gibbs' free energy variation $\Delta G=-T_{o} \Delta S$ (Callen, 1985). When isolating one mole of a particular species of low content $x$ in a mixture, one simply has:

$$
\Delta G=R T_{o}(-1+\log x)
$$

The minimum energy required to isolate a minor component, exhibiting a logarithmic variation would then be relatively small; however this is so assuming an ideal mixture, when entropy is solely a measure of information; it will be differently when the concrete nature of the particles and their interaction are taken in account in the entropy function. If the interactions are no longer negligible, an appropriate factor $\gamma_{i}<1$ must be affected to each $x_{i}$ to account, for instance, for the activity of the ions in a solution or the interfacial energy between mineral grains in a rock matrix, so that $\log x_{i}$ must be replaced by $\log \gamma_{i} x_{i}$ (Rosa and Rosa, 2006b).

Mixtures of particles when having quite different properties require smaller amounts of energy to be separated than when the properties are rather similar. A separation means an applied field and a flow, high intensity fields being required when species' differences are small. Large gradients (for separation) and large flows (for throughput) mean having conditions far from equilibrium and therefore significant energy dissipation, that is, entropy generation and exergy loss. That is why little energy is spent and high yield is attained in separating gold nuggets from gravel, whereas very much energy is spent and low yield is attained in separating the uranium isotopes.

That is also why a cascade of operating units is necessary to attain the desired separation, when the degree of separation is low in a single unit operation. Figure 6 illustrates the separation cascade concept; it represents schematically a one dimensional 
cascade, which processes a feed input to deliver a higher grade output at one end and lower grade output at the other.

Figure 6 Scheme of a one dimensional cascade of separation units. In a two dimensional cascade units are associated both in parallel and series

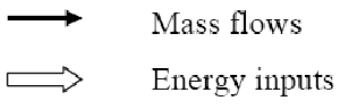

Product

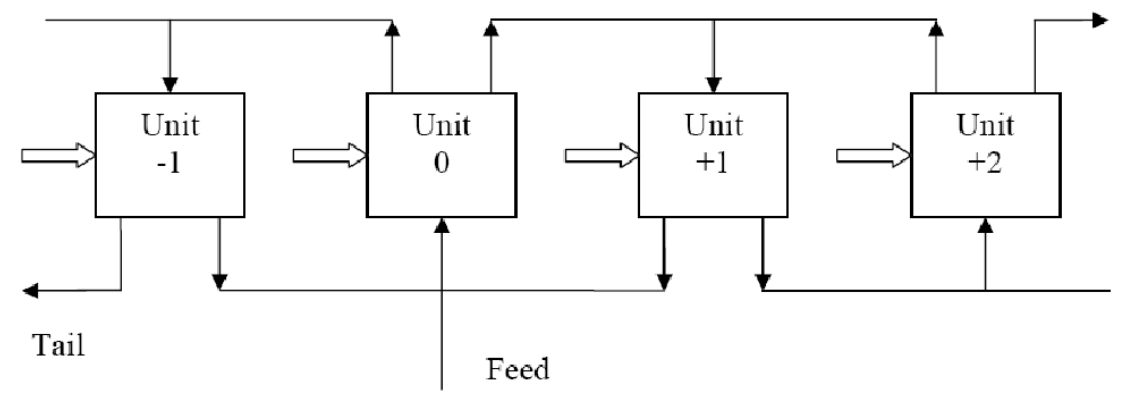

The fundamental property which is changed when separating different species in a mixture is entropy. A separation or un-mixing device receives a feed input and delivers a enriched output (or product) plus a depleted output (tail or waste); these two outputs constitute a less disordered system than the incoming feed material. This means that the entropy of the material flow has been decreased in the separation process, at the expense of consumed exergy (incorporated in the product apart losses and wastes), whose magnitude is given by $T_{o} \Delta S$.

Let us look into two relevant case studies to illustrate the physics of separation and the associated exergy requirements.

\subsection{Uranium isotopic separation}

Uranium isotopic separation is a case study of general interest whenever individual separation steps deliver a small separation gain and a large cascade of separation units, connected in forward and backward senses process an increasingly enriched (product) and an increasingly depleted (waste or tail) streams. The design of such two dimensional cascades, arranged in series and parallel connections, is of great importance to reduce overall energy consumption, given the flow and the grade of feed $F, x_{F}$, product $P, x_{P}$ and waste $T, x_{T}$ streams as constraints (Krass et al., 1983).

Each separation unit can be visualised as absorbing exergy and converting it into order, or reducing the entropy of the material flow. The entropy change produced by a separation unit per unit of feed is given by:

$$
\Delta S=\frac{1}{2} K g^{2} \theta(1-\theta) \frac{x_{F}}{\left(1-x_{F}\right)} \quad g=q-1 \quad q=\frac{x_{p}\left(1-x_{T}\right)}{x_{T}\left(1-x_{p}\right)}
$$

$q$ being the separation factor, $g=q-1$ the separation gain, and $\theta=P / F$ the ratio of product to feed mass flow; $K$ is a constant in entropy units. This expression for the 
entropy reduction per step is valid as long as the effect of a single separative unit is small, that is as long as $\mathrm{g}<<1$.

In a cascade, each separation unit produces a different entropy change, depending of its locations, because of the differences in feed composition along the cascade. There is no simple relation between energy spent and entropy reduction per separation unit. This fact has led to conceiving a separative work quantity, which can be attributed to each separation unit independently of its position in the cascade and of the composition of the feed, depending only on throughput and the change in concentration achieved, and being nearly proportional to the rate of energy consumption. The value function $V(x)$ defined to yield a separative work satisfying the said properties is given by (Krass et al., 1983; Urenco, 2005):

$$
V(x)=(2 x-1) \log \left(\frac{x}{1-x}\right)
$$

displaying a nearly linear evolution centred at $x=1 / 2$ in a linear-log graph.

The change in value produced by each separation unit measures the separative work realised (Krass et al., 1983)

$$
\Delta V=\frac{1}{2} g^{2} \theta(1-\theta) F
$$

This quantity, having formal analogy to the entropy change, has however the same dimensions as the feed (mass or flow rate), but is measured in separative work units (kg SWU or kg SWU/year). For the whole plant, the separative work realised can be calculated from the mass amounts and grades of feed, waste and product, with the help of the value function (URENCO, 2005):

$$
\Delta V=P V\left(X_{F}\right)+T V\left(X_{T}\right)-F V\left(X_{F}\right) .
$$

This amount is proportional to the energy expenditure in the separation cascade. A number of isotope separation methods are available, achieving different separation gains and demanding different energy costs. Modern gaseous diffusion plants typically require $9 \mathrm{GJ}$ of electrical energy per $\mathrm{kg}$ SWU while gas centrifuge plants require just $200 \mathrm{MJ}$ per kg SWU.

Given natural uranium $(0.7 \% \mathrm{U}-235)$ to attain a given enrichment grade (say $3 \%$ $\mathrm{U}-235)$, the recovery ratio $\theta=P / F$ increases with separative work spent, leaving an increasingly depleted waste or tail. Per unit mass of specified grade product, less natural uranium feed is required by spending more separative work; or more natural uranium feed is required when reducing the separative work expenditure. In practice a trade off is sought, on economic rather than on exergetic grounds, that deserves further study.

The concept is no longer useful for a small number of stages having a relatively large separation gain per stage.

\subsection{Water desalination}

Fresh water is a renewable resource. The replenishing rate of funds is fast for surface waters but is very much slower for most aquifers and glaciers. Its flow is driven by the climate engine and represents a small branch of the planetary exergy flow. Its environment reference state is seawater at sea level. Fresh water exists as a limited 
flow and is scarce over large parts of the World. Where its supply is scarce one can pose the question of the 'exergy replacement cost' of fresh water from available seawater (or from brackish water) (The Exergoecology Portal, 2007).

The most reliable methods of seawater desalination are rated into three categories according to the elected property and the separation technique, namely (United Nations, 2001): by exploring a change of phase (freezing or distillation); or ion diffusion and mobility, employing membranes (reverse osmosis and electro-dialysis); or chemical affinities (ion exchange through an interface). The energy carrier driving the process varies with the method; it can be thermal, mechanical or electrical.

Large technical improvements have been attained in water desalination or depuration. Over the last 30 years, the energy intensity in seawater desalination plants has experienced a ten fold decrease, supported in shifting methods and added energy recovery devices. Reverse osmosis displaced multistage flash distillation, and expansion turbines and pressure exchangers recover otherwise wasted mechanical work.

Desalination is carried out in single or multistage individual units or in short cascades. Each unit realises a certain degree of separation that depends on the salinity of the feed and product streams, and on the ratio of these two flows; the mass and salinity of the waste stream stays determined by the water and salt mass balances. The minimum energy required to attain a desired recovery ratio $\theta=P / F$ of product $P$ vs. feed $F$ mass flows, at given salinity molar fractions of product $x_{P}$ and feed $x_{F}$, has been modelled, assuming ideal solutions. Such minimum work requirement is the exergy increment between the input and output flows. The desalination exergy has been summarised in the formula (for pure product at null salinity $x_{p}$ ) given at The Exergoecology Portal (2007):

$$
b_{\mathrm{des}}=\frac{R_{H 20} T_{o}}{\theta} \frac{x_{F}}{1-x_{F}} \log \left(\frac{1}{1-\theta}\right) .
$$

Typical seawater ( $3.5 \%$ of salt) has a minimum work of separation of $1.477 \mathrm{~kJ} / \mathrm{kg}$ for pure water produced at zero recovery ratio. The minimum work requirement increases rapidly for recovery ratios larger than about $80 \%$, and reaches its maximum value of $8.169 \mathrm{~kJ}$ at $100 \%$ recovery. The separation work always increases with the salinity of the feed, the increase being nearly linear at low salinities; and the highest value of the required work can become several times the lowest value (University of Nevada, 2003).

\section{Actual exergy efficiency}

Consider a mining operation that extracts ore from a mine, to separate the mineral(s) of interest from the gangue in a succession of grinding, milling and concentration stages, and eventually on to chemical separation of one or more chemical species, by appropriate metallurgical means such as smelting and refining. The targeted mineral is present at an ever higher concentration at successive stages along the processing stream. This upgrade requires other material flow inputs, such as water and chemical reagents in the milling and separation processes, and the expenditure of energy to power the mining, milling and concentrating equipments, to heat the smelting furnaces, and to electro-win the metallic elements. Waste materials and waste heat flows are ultimately released to the environment at every stage, while the desired product is passed on for further production and final use (Ruth, 1995). 
Part of the high quality (low entropy) energy inputs into these processes is wasted or irreversibly degraded and released to the environment, and part leaves the process as high quality chemical exergy, embodied in the material output.

Mass or energy flow analysis and life-cycle assessments have been carried out of lately by an increasing number of researchers, aiming at studying the full impact and real sustainability of the current exploitation of mineral resources; it is very difficult, though, to achieve complete life-cycle assessments, due to lack of the required data. Raw-material extraction and processing imply proportionally much larger mass and energy expenditures than the final mass and the chemical exergy embodied in commodity. It is useful to measure input and output flows of mass as well as of the associated exergy flows, and the utility exergy supplied, to assess both mass and exergy balances. Ayres et al. (2002, 2006), and others compiled extensive data mostly on the industrial experience of the US economy in order to assess the exergetic efficiency of the mining and extracting metallurgy industries in a highly developed technological environment.

Taking the well documented case of the primary production of an important commodity such as copper in the USA (Masini et al., 2001), the aggregate mass and energy balances on annual basis show that for a mass input of $204 \mathrm{Tg}$ (190 $\mathrm{Tg}$ of ores plus $8.1 \mathrm{Tg}$ of air and water and $5.4 \mathrm{Tg}$ of chemical agents) corresponding to $68 \mathrm{GJ}$ of embodied exergy, the final output is $1 \mathrm{Tg}$ of copper plus $0.67 \mathrm{Tg}$ of other metallic by-products, corresponding to 3.22 GJ of embodied exergy; utility exergy input to the whole process is $45.3 \mathrm{GJ}$, whereas waste mass is $202 \mathrm{Tg}$ corresponding to $21.4 \mathrm{GJ}$ of embodied exergy; the exergy loss (waste heat) is 90 GJ. One realises that the overall mass and exergy efficiencies are both of order $1: 100$, which is rather low, although profiting from the best technologies available, but given the declining ore grade now at about $0.6 \%$, portraying the economic constraints imposed by natural law. Comparable results were obtained for other base metals, the situation being rather more favourable with iron and aluminium - commodities extracted from ores with much higher grades.

Valero and Botero (2002) and Valero et al. (2006) compiled data on the theoretical exergy of substances as they occur in mineral deposits and of mineral products extracted from them, with reference to the standard reference environment. They further examined the actual exergy expenditure of the industry in producing mineral products from their mineral deposit sources, and defined unit exergy cost $k$ as the ratio of the actual industrial exergy expended to the theoretical value in ideal conversions. They addressed separately a chemical exergy component, associated to the free energy of chemical elements and compounds, and a concentration exergy component, associated with the mixing entropy of substances, and computed the corresponding unit exergy costs of industrial products.

Table 1 shows the concentration and the chemical unit exergy costs $-k_{\text {conc }}$ and $k_{\text {chem }}$ - of some important commodities computed by Valero et al. (2002) and Valero et al. (2006); one realises that as a rule unit concentration exergy costs are one or several orders of magnitude larger than corresponding unit chemical exergy costs.

The actual concentration unit exergy cost $k_{\text {conc }}$ varies widely, from 1 in the case of magnesium to more than 400,000 for gold. The latter value is an indication of how difficult it is to obtain gold, for occuring at very low concentrations, and how low is the efficiency of the lengthy process by means of which it is separated from the crust. According to Valero and Botero (2002), the unit exery costs for the concentration of most common and base metals, such as $\mathrm{Al}, \mathrm{Zn}, \mathrm{Cu}, \mathrm{Fe}, \mathrm{Ni}, \mathrm{Pb}$, Ti, etc., fall between 100 and 400. Some mineral products, which are currently obtained as by-products from the recovery of other elements, have significantly high concentration unit costs, such as 
germanium (313), gallium (1061) and indium (2502), given their scarcity and/or high dispersion in the Earth's crust (elements not constituting minerals of their own and/or not concentrating in ore deposits). Notice this data refers to diverse types of rock and ore and that diverse separation routes are employed in this ensemble of study cases.

Table 1 Unit exergy costs of six base and precious metals

\begin{tabular}{lrc}
\hline Metal & $k_{\text {conc }}$ & $k_{\text {chem }}$ \\
\hline $\mathrm{Ag}$ & 7042 & 1 \\
$\mathrm{Au}$ & 422879 & 1 \\
$\mathrm{Cu}$ & 343 & 80 \\
$\mathrm{Ni}$ & 432 & 58 \\
$\mathrm{~Pb}$ & 219 & 25 \\
$\mathrm{Zn}$ & 126 & 13 \\
\hline
\end{tabular}

Source: Valero et al. (2006)

The chemical unit exergy cost $k_{\text {chem }}$ of metals (which is most relevant at the refining stage) is normally much smaller than the unit exergy cost of concentration. In the cases of aluminium and iron, $k_{\mathrm{chem}}$ is 7.8 and 4.2 respectively, compared to $k_{\mathrm{conc}}$ values of 395 and 44 , respectively.

The reciprocal of the unit exergy costs are estimates of the exergy efficiency, so that it assesses the efficiency of the processing routes and the available technology. The obtained results point to very low exergetic efficiencies in extracting mineral resources, demonstrating how far ores and concentrates are from ideal behaviour, and technologies from reversibility conditions. One should realise that extracting and concentrating mineral commodities, particularly those occurring in low grade reservoirs, are intrinsically very costly processes. And one ought to realise the limits to the growth of production of certain mineral products.

\section{Conclusion}

The actual concentration exergy expenditures incurred by the mining and ore beneficiation industry are one or several orders of magnitude larger than the corresponding theoretical values, and the actual chemical exergy expenditures by the extractive metallurgy industry downstream.

The geological and physical-chemical factors behind the high exergy demand in producing mineral commodities are identified. Processes can be improved, but fundamental constraints cannot be removed, namely declining ore grades, limited recovery rates at every processing stage, finite gradients and throughputs in the separation of mineralogical species, and theoretical exergy costs. Overall, technical efficiency improvements are countered by the impact of inevitable decline in ore grades (depletion). 
The exploitation of resources of declining quality imply a long time trend of increasing mass and exergy flow inputs spent per unit product output. The extraction of mineral natural capital, as assessed in exergy units, faces a law of 'diminishing returns'.

\section{References}

Ayres, R.U., Ayres, L.W. and Råde, I. (2002) 'The life cycle of copper, its co-products and by-products', International Institute for Environment and Development (IIED), Mining, Minerals and Sustainable Development project, report 24. CMER, INSEAD, Fontainebleau, France.

Ayres, R.U., Ayres, L.W. and Masini, L. (2006) 'An application of exergy accounting to five basic metal industries', Sustainable Metals Management, Springer, Netherlands, pp.141-194.

Callen, H.B. (1985) Thermodynamics and An Introduction to Thermostatics, John Wiley \& Sons, New York.

Cargill, S.M., Root, D.H. and Bailey, E.H. (1981) 'Estimating usable resources from historical industry data', Economic Geology, Vol. 76, pp.1081-1095.

Chapman, P.F. and Roberts, F. (1983) Metal Resources and Energy, Butterworths, London.

Charles, R.J. (1957) 'Energy-size relationships in comminution', Transactions AIME/SME, Vol. 208, pp.80-88.

Cox, D.P. and Singer, D.A. (1986) 'Mineral deposit models', US Geological Survey Bulletin, 1693.

Cranstone, D.A. (2002) A History of Mining and Mineral Exploration in Canada and Outlook for the future, Natural Resources of Canada, Minerals and Metals Sector, Ottawa, Ontario.

Cranstone, D.A. (2003) Outlook for Canadian Mine Production, Mine Life and Ore Reserves, Natural Resources of Canada, Minerals and Metals Sector. Ottawa, Ontario.

de Vries, B. (1988) Sustainable Resource Use, Optimal Depletion with a Geostatistical Framework, IVEM report nr. 35, Groningen.

Donovan, J.G. (2003) Fracture Toughness based Models for the Prediction of Power Consumption, Product Size, and Capacity of Jaw Crushers, Dissertation submitted to the Faculty of the Virginia Polytechnic Institute and State University, PhD, in Mining and Minerals Engineering. Blacksburg, VA.

Harris, D.P. (1984) Mineral Resource Appraisal, Oxford University Press, New York.

International Atomic Energy Agency (1996) Steps for Preparing Uranium Production Feasibility Studies: A Guidebook, report IAEA-TECDOC-885, IAEA, Vienna.

Kellogg, H.H. (1977) 'Sizing up the energy requirements for producing primary metals', Engineering and Mining Journal, Vol. 178, No. 4, pp.61-65.

Krass, A.S., Boskma, P., Elzen, B. and Smit, W.A. (1983) Uranium Enrichment and Nuclear Weapon Proliferation: Chapter 5 General Principles of Uranium Enrichment, Taylor and Francis Ltd., London.

Lasky, S.G. (1950) 'How tonnage and grade relations help predict ore reserves', Engineering and Mining Journal, Vol. 151, No. 4, pp.81-85.

Masini, A., Ayres, L.W. and Ayres, R.U. (2001) An Application of Exergy Accounting to Five Basic Metal Industries, Working paper 2001/32/EPS/CMER. CMER, INSEAD, Fontainebleau, France.

Mudd, G.M. (2005) Inquiry into the Development of the Non-fossil Fuel Energy Industry in Australia: Case Study into the Strategic Importance of Australia's Uranium Resources, House of Reps Australian Uranium Resources Inquiry, Standing Committee on Industry \& Resources, House of Representatives, Parliament of Australia, Canberra.

Nagahama, H. and Yoshii, K. (1994) 'Scaling laws of fragmentation', in Kruhl, J.H. and Fractals, J.H. (Eds.): Dynamic Systems in Geosciences, Springer-Verlag, Berlin, pp.25-36. 
Norgate, T.E. and Lovel, R. (2004) Water Use in Metal Production: A Life Cycle Perspective, CSIRO Minerals, Report DMR-2505, Australia.

Norgate, T.E. and Rankin, W.J. (2000) 'Life cycle assessment of copper and nickel production. In: MINPREX 2000', Proc. International Conference on Minerals Processing and Extractive Metallurgy, Melbourne, pp.133-138.

Norgate, T.E. and Rankin, W.J. (2002) The Role of Metals in Sustainable Development, CSIRO Minerals, Australia

Rosa, D.R.N. and Rosa, R.N. (2006a) 'The availability and depletion of copper: the Iberian pyrite belt scenario', Program of the XII IAGOD Symposium, Moscow, p.102.

Rosa, R.N. and Rosa, D.R.N. (2006b) 'Assessing mineral reserves in energy terms', Proc. VII Congresso Nacional de Geologia, Évora, Portugal, Vol. 3, pp.1055-1058.

Ruth, M. (1995) 'Thermodynamic constraints on optimal depletion of copper and aluminium in the United States: a dynamic model of substitution and technical change', Ecological Economics, Vol. 15, pp.197-213.

Sammis, C., Osborn, R., Anderson, J., Banerdt, M. and White, P. (1986) 'Self-similar cataclasis in the formation of fault gouge', Pure Appl. Geophys., Vol. 123, pp.53-78.

Singer, D.A. (1993) 'Basic concepts in three-part quantitative assessments of undiscovered mineral resources', Nonrenewable Resources, Vol. 2, No. 2, pp.69-81.

Skinner, B.J. (1979) 'Earth resources', Proc. Natl. Acad. Sci. USA, Vol. 76, No. 9, pp.4212-4217.

Sychev, V.V. (1981) Complex Thermodynamic Systems, MIR Publishers, Moscovo.

Szargut, J. (2005) Exergy Methods: Technical and Ecological Applications, WIT Press, Southampton.

The Exergoecology Portal (2007) The Exergy Replacement Cost of Natural Mineral Capital, The Exergoecology Portal, Retrieved March 2007 at http://www.exergoecology.com/

Turcotte, D.L. (1992) Fractals and Chaos in Geology and Geophysics, Cambridge University Press, Cambridge.

United Nations (2001) Water Desalination Technologies in the ESCWA Member Countries, Economic and Social Commission for Western Asia, Publication E/ESClA/TECH/2001/3, United Nations, New York.

US Geological Survey (2006) Copper Statistics, in Kelly, T.D. and Matos, G.R. (comps.): Historical Statistics for Mineral and Material Commodities in the United States, US Geological Survey Data Series 140, available on line at http://pubs.usgs.gov/ds/2005/140/

University of Nevada (2003) Improving the Thermodynamic and Economic Efficiencies of Desalination Plants: Minimum Work Required for Desalination and Case Studies of Four Working Plants, Desalination and Water Purification Research and Development Program, Final Report No. 78, University of Nevada, Reno, Nevada.

University of Sydney (2006) Life-cycle Energy Balance and Greenhouse Gas Emissions of Nuclear Energy in Australia: A Study Undertaken for the Department of Prime Minister and Cabinet of the Australian Government, ISA, The University of Sydney.

Urenco (2005) 'Uranium enrichment. Urenco Deutschland GmbH', Urenco Informationszentrum, Retrieved September at http://www.urenco.de

Valero, A. and Botero, E. (2002) 'Exergetic evaluation of natural mineral capital (2) Application of the methodology to current world reserves', in Tsatsaronis, G., Cziesla, F. and Bruckner, T. (Eds.): Proc. ECOS 2002, Berlin, pp.62-68.

Valero, A., Ranz, L. and Botero, E. (2002) 'Exergetic evaluation of natural mineral capital (1) Reference environment methodology', in Tsatsaronis, G., Moran, M., Cziesla, F. and Bruckner, T. (Eds.): Proc. ECOS 2002, Berlin, pp.54-61.

Valero, A., Valero, A., Martínez, A. and Mudd, G. (2006) 'A physical way to assess the decrease of mineral capital through exergy, The Australian case', Ninth Biennial Conference on the International Society for Ecological Economics (ISEE), New Delhi. 
van Leeuwen, J.W.S. (2006) Energy from Uranium, Oxford Research Group, Retrieved February 2007, Oxford, at www.oxfordresearchgroup.org.uk/

van Leeuwen, J.W.S. and Smith, P. (2005) Nuclear Power - The Energy Balance: Chapter 2: From Ore to Electricity Energy Production and Uranium Reserves (Sixth Revision), Chaam, Nuclear power - the energy balance, Netherlands, retrieved February 2007 at http://www.stormsmith.nl/ 